\section{ESTRUTURA DAS TAREFAS DE TREINAMENTO EM MODALIDADES ESPORTIVAS COLETIVAS: ANÁLISE DA PRODUÇÃO CIENTÍFICA}

\author{
STRUCTURE OF PRACTICE TASKS IN COLLECTIVE SPORTS: ANALYSIS OF \\ SCIENTIFIC PRODUCTION
}

\author{
ESTRUCTURA DE LAS TAREAS DE ENTRENAMIENTO EN MODALIDADES \\ DEPORTIVAS COLECTIVAS: ANÁLISIS DE LA PRODUCCIÓN CIENTÍFICA
}

\author{
Eduardo José Dallegrave*, Alexandra Folle*, Vinícius Plentz de Oliveira*, \\ Juarez Vieira do Nascimento**
}

Keywords: and Practice.

Sports.

Task Analysis and Performance.
Physical Education

Resumo: $O$ objetivo deste estudo foi mapear as investigações que analisaram a estrutura das tarefas de treinamento em equipes de categorias de formação de modalidades esportivas coletivas, considerando as variáveis pedagógicas (tipo de conteúdos, fases de jogo e situações de jogo) e organizativas (tempo total da tarefa, tempo útil e tipo de participação). Foram empregadas três buscas de informação: bases de indexação; sites de periódicos; e referências dos artigos rastreados nas duas primeiras buscas. A abrangência temporal dos estudos correspondeu aos anos de 2000 a 2017. Os resultados elucidaram que, nas variáveis pedagógicas, as tarefas pautaram-se em treinamentos de condutas táticas (tipo de conteúdo), de ações mistas (fases de jogo) e situações de igualdade numérica (situações de jogo). Na variável organizativa, as tarefas indicaram predomínio da participação consecutiva nos treinamentos (tipo de participação).

\begin{abstract}
This study maps research on the structure of practice tasks in teams from beginner categories in collective sports modalities, considering pedagogical (type of content; game stages; and game situations) and organizational (total time of the task; useful time; and type of participation) variables. Three information searches were conducted: on indexation databases; journal's websites; and references from the articles found in the first two searches. The studies' time scope was 2000-2017. The results showed that, regarding pedagogical variables, tasks were based on tactical behaviors (type of content), mixed actions (game stages), and situations of numerical equality (game situations). Regarding the organizational variable, the tasks indicated predominance of consecutive participation in the practice (type of participation).
\end{abstract}

Palabras clave: Educación Física y Entrenamiento. Deportes. Análisis y Rendimiento de Tareas
Resumen: El objetivo de este estudio fue mapear las investigaciones que analizaron la estructura de las tareas de entrenamiento en equipos de categorías de formación de modalidades deportivas colectivas, considerando las variables pedagógicas (tipo de contenidos, fases de juego y situaciones de juego) y organizativas (tiempo total de la tarea, tiempo útil y tipo de participación). Se utilizaron tres búsquedas de información: bases de indexación; sitios web de periódicos; y referencias de los artículos rastreados en las dos primeras búsquedas. El alcance temporal de los estudios correspondió a los años 2000 a 2017. Los resultados elucidaron que, en las variables pedagógicas, las tareas se pautaron en entrenamientos de conductas tácticas (tipo de contenido), de acciones mixtas (fases de juego) y situaciones de igualdad numérica (situaciones de juego). En la variable organizativa, las tareas indicaron predominio de la participación consecutiva en los entrenamientos (tipo de participación)...
*Universidade do Estado de Santa Catarina. Florianópolis, SC, Brasil. E-mail: edudallegrave@gmail.com; afolle_12@ hotmail.com; viniciusplentz@hotmail.com

**Universidade Federal de Santa Catarina. Florianópolis, SC, Brasil. E-mail: juarez.nascimento@ufsc.br

Recebido em: 19-01-2018 Aprovado em: 19-07-2018

DOI: https://doi.org/10.22456/1982-8918.79792 (c) (1) (8) Licence 


\section{INTRODUÇÃO}

O esporte tem sido alvo de estudos de distintas áreas do conhecimento, que contemplam enfoques e procedimentos diversificados para auxiliar na melhoria da formação de jogadores, no desenvolvimento profissional de treinadores e, principalmente, no alcance de patamares de qualidade cada vez mais elevados da performance esportiva. Nesse cenário investigativo, a Pedagogia do Esporte, área do conhecimento no interior das Ciências do Esporte (GALATTI et al., 2014; GALATTI et al., 2015; MACHADO; GALATTI; PAES, 2014), tem lançado olhar especial aos ambientes favoráveis à prática esportiva, focalizando tanto no âmbito da educação e da participação quanto do âmbito competitivo. Além disso, investigações nessa área têm buscado refletir especialmente sobre os procedimentos pedagógicos e os delineamentos dos processos de ensino, vivência, especialização, aprendizagem e treinamento esportivo, aos quais jovens atletas têm sido submetidos (GALATTI et al., 2014; MACHADO; GALATTI; PAES, 2014).

No que tange ao treinamento esportivo, evidencia-se a importância da análise do planejamento e da organização das tarefas ministradas pelos treinadores durante as sessões de treino (IBÁÑEZ; FEU; CAÑADAS, 2016). Contudo, apesar da reconhecida relevância da pesquisa científica relacionada aos aspectos pedagógicos do treinamento esportivo, em especial da estruturação das tarefas de treino (CAÑADAS; SOLBES; FEU, 2015; IBÁÑEZ; JIMÉNEZ; ANTÚNEZ, 2015), esta ainda se apresenta escassa em comparação a dos aspectos fisiológicos (KUNRATH et al., 2016; PEIXOTO et al., 2016), biomecânicos (BENJAMINSE et al., 2017; FICKLIN; DAPENA; BRUNFELDT, 2016) e psicológicos (FORTES et al., 2017;MACHADO et al., 2016) voltados ao desempenho esportivo.

A relevância das evidências encontradas nessas diferentes dimensões de análise do fenômeno esportivo reforça também a necessidade de análises das produções científicas divulgadas, visando-se apresentar o estado da arte em torno de determinados aspectos pedagógicos do treino, bem como do quanto essas investigações têm sido sugestivas ou conclusivas em seus achados. Nesta perspectiva, enfatiza-se a pertinência da análise das pesquisas conduzidas na área da Pedagogia do Esporte, no âmbito do treinamento esportivo, em especial no que tange às tarefas de treinamento técnico-tático (COLLET; DONEGÁ; NASCIMENTO, 2009). O destaque atribuído às tarefas de treino se reporta ao reconhecimento de que a investigação da estruturação das tarefas de treino se apresenta, atualmente, como uma das linhas investigativas mais emergentes dentro da Pedagogia do Esporte (IBÁÑEZ; FEU; CAÑADAS, 2016).

Nesse cenário, destaca-se que as exigências em torno do rendimento esportivo vêm impondo uma seleção cada mais criteriosa das tarefas que fazem parte das sessões de treinamento no processo de formação esportiva. Neste caso, o envolvimento de crianças e jovens em modalidades esportivas coletivas tem sido discutido ao longo dos anos, apontando que ainda existe uma controvérsia entre o treinamento de alto rendimento e o treinamento no processo formativo, além de se reconhecer que esse treinamento nem sempre está respaldado no rigor científico, não havendo suporte empírico consistente para as hipóteses formuladas sobre as possíveis consequências desse treinamento no desenvolvimento da criança e do jovem (COLLET; DONEGÁ; NASCIMENTO, 2009).

As tarefas de treino têm sido analisadas, especialmente, a partir de variáveis pedagógicas e organizativas. Enquanto as variáveis pedagógicas reportam informações sobre 0 tipo de 
conteúdo (condutas tático-técnicas e gestos técnico-táticos), a fase de jogo (ataque, defesa e mista) e as situações de jogo (igualdade, superioridade ou inferioridade numérica), a variável organizativa fornece informações sobre o tempo de duração das tarefas (total, explicação, útil) e o tipo de participação dos atletas na tarefa (simultânea, consecutiva e alternada) (IBÁÑNE; FEU; CAÑADAS, 2016).

Diante da importância da Pedagogia do Esporte dentro das áreas de conhecimento voltadas ao estudo do esporte e do alargamento do nível de compreensão dos aspectos pedagógicos do treinamento esportivo, o objetivo deste estudo foi mapear as investigações que analisaram a estrutura das tarefas de treinamento de equipes de categorias de formação de modalidades esportivas coletivas, considerando as variáveis pedagógicas e organizativas.

\section{PROCEDIMENTOS METODOLÓGICOS}

O presente estudo se caracteriza como uma investigação teórica, no formato de revisão sistemática da literatura (MONTERO; LEÓN, 2007), a qual se caracteriza como uma atualização de estudos teóricos, desenvolvendo um processo sistemático de acumulação dos dados (ATO; LÓPEZ; BENAVENTE, 2013). Para operacionalização do estudo, seguiram-se os procedimentos indicados na ficha de revisão sistemática desenvolvida por Saur-Amaral (2012): equações de pesquisa; âmbito da pesquisa; aspectos técnicos; critérios de inclusão e exclusão; critérios de qualidade e validade metodológica; filtragem dos resultados.

Com relação às equações de pesquisa, destaca-se que foram elaboradas a partir da combinação de descritores, os quais foram associados por meio do operador Booleano AND e do facilitador de pesquisa*, para otimizar a busca pelas fontes de informação (Quadro 1):

Quadro 1 - Equações de pesquisa.

\begin{tabular}{|c|c|c|}
\hline Português & Inglês & Espanhol \\
\hline Treinamento AND Esporte* & Teaching AND Sport* & Entrenamiento AND Deporte* \\
\hline $\begin{array}{c}\text { Treinamento técnico e tático AND } \\
\text { Esporte* }^{*}\end{array}$ & $\begin{array}{l}\text { Technical and tactical training } \\
\text { AND Sport* }\end{array}$ & $\begin{array}{l}\text { Entrenamiento técnico y táctico } \\
\text { AND Deporte* }\end{array}$ \\
\hline Treinamento técnico AND Esporte* & Technical training AND Sport* & $\begin{array}{c}\text { Entrenamiento técnico AND } \\
\text { Deporte* }^{*}\end{array}$ \\
\hline Treinamento tático AND Esporte* & Tactical training AND Sport* & $\begin{array}{c}\text { Entrenamiento táctico AND } \\
\text { Deporte* }\end{array}$ \\
\hline
\end{tabular}

Fonte: Elaborado pelos autores.

O âmbito da pesquisa envolveu os locais de buscas dos manuscritos, os campos de pesquisa e as áreas temáticas. Assim, destaca-se que a localização e a identificação dos artigos ocorreram em três momentos distintos:

- Pesquisa primária: busca de artigos científicos nas bases de indexação LILACS, SciELO, Scopus e Web of Science, as quais foram selecionadas por serem empregadas no processo de avaliação da produção bibliográfica da área 21 na Capes (estratos A1 a B2);

- Pesquisa secundária: realizada diretamente nos sites dos periódicos científicos que, durante a busca primária, resultaram na seleção de manuscritos para análise. Esse segundo momento é justificado pelo interesse na ampliação da abrangência da busca, considerando 
que os descritores utilizados pelas bases de indexação nem sempre correspondem às palavras-chave utilizadas pelos periódicos e nem sempre conseguem representar a temática dos estudos, bem como algumas bases demoram para atualizar as publicações mais recentes e já disponíveis nos periódicos;

- Pesquisa terciária: levantamento de artigos diretamente nas referências dos estudos rastreados, nas buscas conduzidas nas bases de indexação e nos periódicos científicos.

As áreas temáticas de busca corresponderam a: Sport Sciences; Sport Pedagogy; Physical Education, Sport Pedagogy; Ciências da Saúde; Ciências do Esporte; Educação Física. A pesquisa envolveu ainda os aspectos técnicos relativos aos filtros selecionados nas bases de indexação (Quadro 2) e a exportação dos dados.

Quadro 2 - Filtros utilizados nas bases de indexação.

\begin{tabular}{|c|c|c|c|c|c|c|c|}
\hline Base & $1^{0}$ & $2^{\circ}$ & $3^{\circ}$ & $4^{\circ}$ & $5^{\circ}$ & $6^{0}$ & $7^{\circ}$ \\
\hline LILACS & $\begin{array}{c}\text { Título/ } \\
\text { resumo/ } \\
\text { assunto }\end{array}$ & $\begin{array}{c}\text { Tipo de } \\
\text { documento }\end{array}$ & $\begin{array}{c}\text { Ano de } \\
\text { publicação }\end{array}$ & Idioma & $\begin{array}{l}\text { Assunto } \\
\text { principal }\end{array}$ & Revista & $\begin{array}{c}\text { Assunto } \\
\text { da } \\
\text { revista }\end{array}$ \\
\hline SCIELO & Resumo & $\begin{array}{l}\text { Tipo de } \\
\text { literatura }\end{array}$ & $\begin{array}{c}\text { Ano de } \\
\text { publicação }\end{array}$ & Idioma & $\begin{array}{l}\text { WoS áreas } \\
\text { temáticas }\end{array}$ & Periódico & \\
\hline SCOPUS & $\begin{array}{c}\text { Article title/ } \\
\text { abstract/ } \\
\text { keywords }\end{array}$ & $\begin{array}{l}\text { Document } \\
\text { type }\end{array}$ & Year & Language & Source type & Keyword & $\begin{array}{l}\text { Source } \\
\text { title }\end{array}$ \\
\hline $\begin{array}{l}\text { Web of } \\
\text { Science }\end{array}$ & Título & $\begin{array}{c}\text { Tipo de } \\
\text { documento }\end{array}$ & $\begin{array}{c}\text { Ano de } \\
\text { publicação }\end{array}$ & Idioma & $\begin{array}{l}\text { Áreas de } \\
\text { pesquisa }\end{array}$ & $\begin{array}{c}\text { Categorias } \\
\text { do Web of } \\
\text { Science }\end{array}$ & $\begin{array}{l}\text { Títulos } \\
\text { da fonte }\end{array}$ \\
\hline
\end{tabular}

Fonte: Elaborado pelos autores.

$\mathrm{Na}$ exportação dos dados utilizou-se o software EndNote, facilitando assim o processo de arquivamento e de organização dos artigos, segundo as equações de pesquisa, as bases de indexação, os periódicos científicos e o rastreamento nas referências. Para uma melhor confiabilidade da pesquisa, todos os passos foram registrados por meio de print screen da página online das bases de indexação e dos periódicos científicos, sendo, posteriormente, arquivados no software Word (resultado da aplicação dos filtros), assim como no EndNote (referência e texto completo dos artigos encontrados).

No que tange aos critérios de inclusão, foram respeitados dois critérios: o primeiro pautado na seleção automática (busca nas bases de indexação e nos periódicos científicos) e o segundo na seleção manual dos estudos (eliminação dos textos duplicados, leitura dos resumos, leitura dos textos completos). A seleção automática correspondeu a: artigos publicados entre os anos 2000 e 2017 (contemplar a produção científica das décadas iniciais do século XXI); artigos originais (estudos de campo) publicados em periódicos científicos (fontes de informação reconhecidas pela comunidade acadêmica); escritos em português, inglês e espanhol. Para os artigos selecionados via referências, além de atender a estes critérios, os manuscritos deveriam estar divulgados em periódicos com classificação correspondente às bases de indexação selecionadas. Por sua vez, a seleção manual (leitura de resumos e textos na íntegra) atendeu aos critérios: abranger temáticas como treinamento técnico-tático, sessões de treinamento esportivo e tarefas de treino, priorizando-se assim os aspectos pedagógicos de treino; abranger atletas das categorias de formação e de modalidades esportivas coletivas. 
De modo similar, também foram elencados critérios de exclusão que passaram pela eliminação automática (artigos escritos em outra língua que não inglês, espanhol ou português e manuscritos publicados em livros, conferências ou anais de eventos) e eliminação manual (artigos de revisão, opinião de especialistas, resenhas críticas, ensaios teóricos ou estudos de validação de instrumentos; artigos originais que abordassem o treinamento a partir do rendimento físico ou de aspectos fisiológicos e/ou que avaliassem atletas da categoria adulta ou de modalidades individuais; artigos originais realizados em aulas de Educação Física).

Os critérios de qualidade e validade metodológica da presente investigação foram: pesquisa validada independentemente por dois investigadores, utilizando os critérios estabelecidos na ficha de pesquisa, atuando um terceiro investigador como consenso, quando de discordância entre os dois primeiros. A última etapa da busca pelos manuscritos envolveu a filtragem dos artigos, a qual pode ser observada na Figura 1:

Figura 1 -Artigos selecionados ao longo das três etapas da pesquisa.

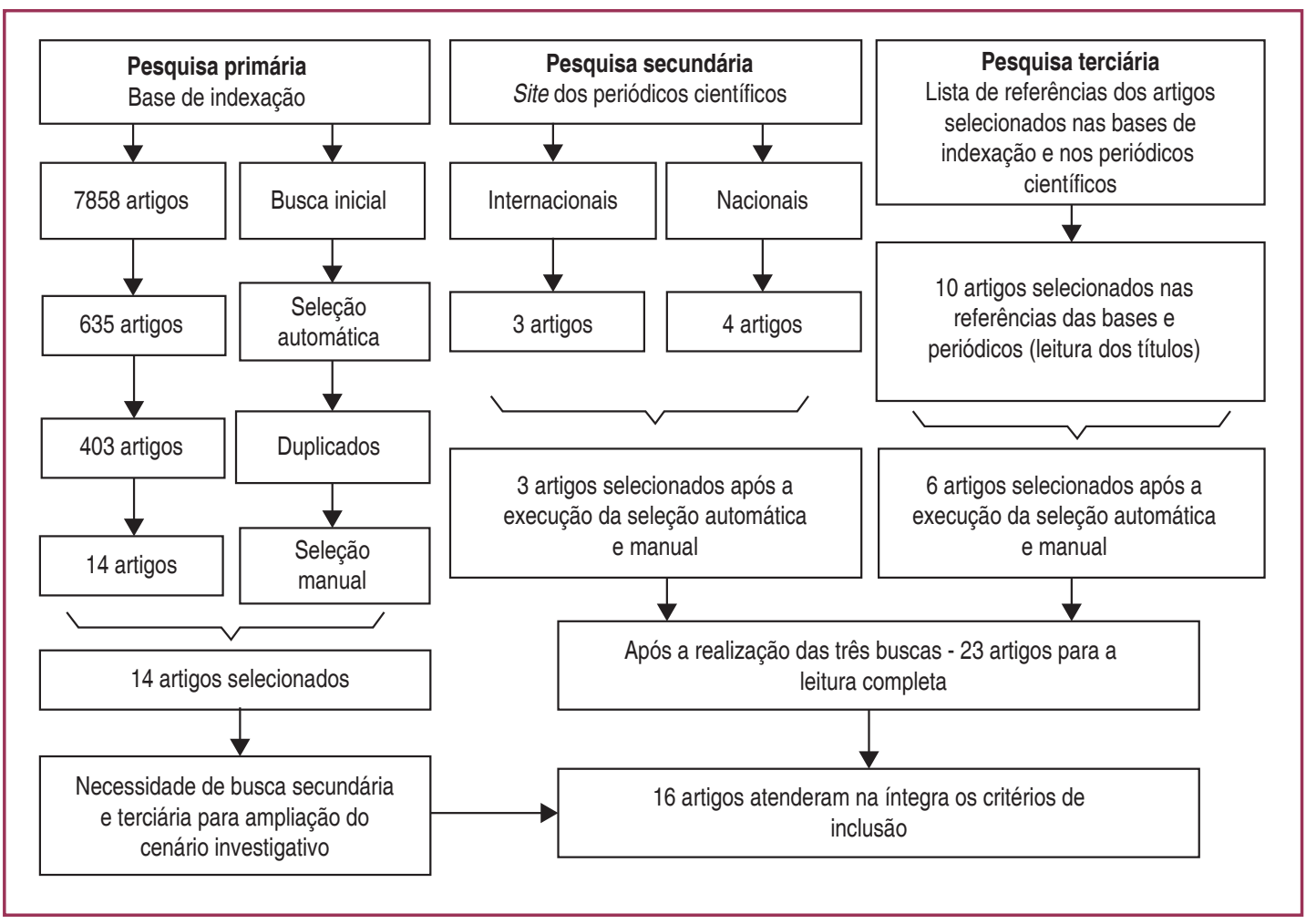

Fonte: Elaborado pelos autores

A versão 11.0 do software NVivo foi utilizada na análise das informações contidas nos artigos originais selecionados no rastreamento dos manuscritos, nomeadamente no preparo dos dados, no processo de codificação e na análise dos dados (GUIZZO; KRZIMINSKI; OLIVEIRA, 2003). Os seguintes procedimentos da técnica de análise do conteúdo foram empregados (CAMPOS, 2004): fase de pré-exploração do material ou de leituras flutuantes; seleção das unidades de análise; processo de categorização e subcategorização (aprioristicamente). Para tanto, as categorias e subcategorias de análise dos artigos originais foram definidas a priori e corresponderam as variáveis pedagógicas e organizativas (Quadro 3) propostas no Sistema Integral de Análise das Tarefas do Treinamento Esportivo (SIATE), de Ibáñez, Feu e Cañadas (2016). 
Quadro 3 - Categorias e subcategorias de análise.

\begin{tabular}{|c|c|}
\hline \multicolumn{2}{|r|}{$\begin{array}{l}\text { Variáveis Pedagógicas } \\
\text { (informações sobre as características das tarefas de treinamento, sobre o conteúdo trabalhado, } \\
\text { sobre o tipo de atividade desenvolvida e sobre a relação entre os atletas nas atividades) }\end{array}$} \\
\hline \multirow{2}{*}{$\begin{array}{l}\text { Tipos de } \\
\text { conteúdos }\end{array}$} & Condutas tático-técnicas (ações táticas individuais e grupais de ataque e defesa) \\
\hline & Gestos técnico-táticos (ações técnicas individuais e grupais de ataque e defesa) \\
\hline \multirow{3}{*}{$\begin{array}{l}\text { Fases do } \\
\text { jogo }\end{array}$} & Ataque (ações predominantemente ofensivas de jogo) \\
\hline & Defesa (ações predominantemente defensivas de jogo) \\
\hline & Mista (ações com foco simultâneo de ataque e defesa) \\
\hline \multirow{3}{*}{$\begin{array}{l}\text { Situações de } \\
\text { jogo }\end{array}$} & $\begin{array}{l}\text { Superioridade numérica (ações de jogo de } 2 \times 1,3 \times 2,4 \times 3 \ldots \text { maior número de atletas na equipe } \\
\text { atacante) }\end{array}$ \\
\hline & Igualdade numérica (ações de jogo de 1x1, 2x2, 3×3...) \\
\hline & $\begin{array}{l}\text { Inferioridade numérica (ações de jogo de 1×2, 2x3, 3×4... maior número de atletas na equipe } \\
\text { defensora) }\end{array}$ \\
\hline \multicolumn{2}{|r|}{$\begin{array}{c}\text { Variáveis Organizativas } \\
\text { (informações sobre a organização dos atletas na tarefa) }\end{array}$} \\
\hline \multirow{3}{*}{ Participação } & Simultânea (participação de toda a equipe na tarefa) \\
\hline & Alternada (uma parte da equipe fica fora, enquanto a outra parte participa da tarefa) \\
\hline & Consecutiva (participação dos atletas em fileiras ou colunas na tarefa) \\
\hline
\end{tabular}

Fonte: Adaptado de lbáñez, Feu e Cañadas (2016).

\section{RESULTADOS}

0 processo de rastreamento dos artigos originais nas bases de indexação, nos periódicos científicos e nas referências dos artigos pré-selecionados, bem como a aplicação dos critérios de inclusão e exclusão, resultou na identificação de 16 produções científicas sobre o processo de estruturação das tarefas de treinamento técnico-tático em modalidades esportivas coletivas. No período de 2000 a 2017 foram identificadas nove publicações em âmbito nacional (Brasil) e sete em âmbito internacional (Quadro 4).

Quadro 4 - Estudos relacionados às tarefas de treinamento, publicados entre os anos de 2000 a 2017.

\begin{tabular}{|l|c|c|c|l|l|}
\hline Autores (Ano) & $\begin{array}{c}\text { Estadol } \\
\text { País }\end{array}$ & Modalidade & Categoria/Sexo & Variáveis & Instrumento \\
\hline $\begin{array}{l}\text { Daolio e Marques } \\
(2003)\end{array}$ & SP/Brasil & Futsal & $\begin{array}{c}\text { Sub 11 e sub 12 } \\
\text { Feminino e } \\
\text { Masculino }\end{array}$ & Fase e Situações & $\begin{array}{l}\text { Observação } \\
\text { sistemática }\end{array}$ \\
\hline $\begin{array}{l}\text { Collet et al. } \\
(2007)\end{array}$ & SC/Brasil & Voleibol & $\begin{array}{c}\text { Sub 15 } \\
\text { Masculino }\end{array}$ & $\begin{array}{l}\text { Conteúdo } \\
\text { Participação }\end{array}$ & Ficha de análise \\
\hline $\begin{array}{l}\text { Morales e Greco } \\
(2007)\end{array}$ & MG/Brasil & Basquete & $\begin{array}{c}\text { Sub 12 } \\
\text { Masculino }\end{array}$ & $\begin{array}{l}\text { Conteúdo, Fase e } \\
\text { Situações } \\
\text { Participação }\end{array}$ & Ficha de análise \\
\hline $\begin{array}{l}\text { Collet, Donegá } \\
\text { e Nascimento } \\
(2009)\end{array}$ & SC/Brasil & Voleibol & $\begin{array}{c}\text { Sub 13 } \\
\text { Masculino }\end{array}$ & $\begin{array}{l}\text { Conteúdo e Situações } \\
\text { Participação }\end{array}$ & Ficha de análise \\
\hline $\begin{array}{l}\text { Silva e Greco } \\
(2009)\end{array}$ & MG/Brasil & Futsal & $\begin{array}{c}\text { Sub 13 } \\
\text { Masculino }\end{array}$ & Conteúdo e Situações & Ficha de análise \\
\hline $\begin{array}{l}\text { Cañadas et al. } \\
(2009)\end{array}$ & Espanha & Basquete & $\begin{array}{c}\text { Sub 11 } \\
\text { Masculino }\end{array}$ & Fase e Situações & PyC Basket 2.0 \\
\hline
\end{tabular}


...continuação do quadro 4.

\begin{tabular}{|l|l|l|c|l|l|}
\hline $\begin{array}{l}\text { Morales, Greco e } \\
\text { Andrade (2009) }\end{array}$ & MG/Brasil & Basquete & $\begin{array}{c}\text { Sub 12 } \\
\text { Masculino }\end{array}$ & Conteúdo & $\begin{array}{l}\text { Observação } \\
\text { sistemática }\end{array}$ \\
\hline $\begin{array}{l}\text { Ford, Yates e } \\
\text { Williams (2010) }\end{array}$ & Inglaterra & Futebol & $\begin{array}{c}\text { Sub 9, sub 13 e } \\
\text { sub 16 Masculino }\end{array}$ & $\begin{array}{l}\text { Conteúdo } \\
\text { sistemática }\end{array}$ \\
\hline $\begin{array}{l}\text { Leite et al. (2011) } \\
\text { Fortugal }\end{array}$ & Basquete & $\begin{array}{c}\text { Feminino e } \\
\text { Masculino }\end{array}$ & Fase e Situações & Entrevista \\
\hline $\begin{array}{l}\text { Lima, Martins- } \\
\text { Costa e Greco } \\
\text { (2011) }\end{array}$ & MG/Brasil & Voleibol & $\begin{array}{c}\text { Sub 13 } \\
\text { Feminino }\end{array}$ & $\begin{array}{l}\text { Conteúdo e Situações } \\
\text { Participação }\end{array}$ & Ficha de análise \\
\hline $\begin{array}{l}\text { Lima, Matias e } \\
\text { Greco (2012) }\end{array}$ & MG/Brasil & Voleibol & $\begin{array}{c}\text { Sub13 e sub 15 } \\
\text { Masculino }\end{array}$ & $\begin{array}{l}\text { Conteúdo e Fase } \\
\text { Participação }\end{array}$ & Ficha de análise \\
\hline $\begin{array}{l}\text { Moreira, Matias e } \\
\text { Greco (2013) }\end{array}$ & MG/Brasil & Futsal & $\begin{array}{c}\text { Sub 10 } \\
\text { Masculino }\end{array}$ & $\begin{array}{l}\text { Conteúdo e Situações } \\
\text { Participação }\end{array}$ & Ficha de análise \\
\hline $\begin{array}{l}\text { Cañadas et al. } \\
\text { (2013) }\end{array}$ & Espanha & Basquete & $\begin{array}{c}\text { Sub 11 e sub 13 } \\
\text { Masculino }\end{array}$ & $\begin{array}{l}\text { Situações } \\
\text { Participação }\end{array}$ & PyC Basket 2.0 \\
\hline $\begin{array}{l}\text { Pérez, Nivela e } \\
\text { Expósito (2014) }\end{array}$ & Espanha & Futebol 8 & $\begin{array}{c}\text { Sub 09 } \\
\text { Masculino }\end{array}$ & Conteúdo Situações & $\begin{array}{l}\text { Match Vision } \\
\text { Studio v3.0 }\end{array}$ \\
\hline $\begin{array}{l}\text { Cañadas, Solbes } \\
\text { e Feu (2015) }\end{array}$ & Espanha & Basquete & $\begin{array}{c}\text { Sub 10 e sub 13 } \\
\text { Masculino }\end{array}$ & $\begin{array}{l}\text { Fase e Situações } \\
\text { Participação }\end{array}$ & PyC Basket 2.0 \\
\hline $\begin{array}{l}\text { lbáñez, Jiménez } \\
\text { e Antúnez (2015) }\end{array}$ & Espanha & Basquete & $\begin{array}{c}\text { Susculino } \\
\text { Participação }\end{array}$ & PyC Basket 2.0 \\
\hline
\end{tabular}

Fonte: Elaborado pelos autores.

A análise das 16 publicações revelou uma quantidade relevante de artigos que foram publicados entre os anos de 2009 e 2015, quando comparados com o período anterior, que teve apenas dois artigos em 2007 e um artigo em 2003. Além de os processos de treinamento, com ênfase na análise das tarefas de treino, compreenderem um foco recente e crescente das investigações na área da Pedagogia do Esporte, evidenciou-se que os estudos foram desenvolvidos predominantemente no Brasil e na Espanha.

Outro aspecto relevante a enfatizar diz respeito às modalidades esportivas coletivas contempladas pelos investigadores, ressaltando-se o predomínio na modalidade de basquetebol, seguida pelas modalidades de voleibol, futsal e futebol, respectivamente. Quanto às categorias de formação mais investigadas, nota-se o predomínio de estudos com as categorias sub 13 e sub 12, demonstrando um interesse inicial dos investigadores pelas primeiras categorias de formação esportiva. Houve também uma quantidade expressiva de investigações que se propuseram investigar somente atletas do sexo masculino.

Com relação aos instrumentos de pesquisa, na realidade brasileira predominou 0 uso da Ficha de análise das sessões de treino proposta por Stefanello (1999), enquanto na realidade espanhola foi o programa informático PyC Basket 2.0. Sobre as principais temáticas contempladas nos estudos sobre tarefas de treino técnico-tático, destacaram-se as variáveis pedagógicas denominadas de tipo de conteúdo, fase de jogo e situação de jogo, bem como a variável organizativa tipo de participação.

A Figura 2 ilustra os principais resultados encontrados nos estudos rastreados, em termos de variáveis pedagógicas priorizadas nas tarefas de treino ofertadas aos atletas de categorias de formação. 
Figura 2 - Resultados em termos de variáveis pedagógicas.

\begin{tabular}{|c|c|c|}
\hline \multicolumn{3}{|c|}{ VARIÁVEIS PEDAGÓGICAS } \\
\hline \multirow{3}{*}{$\begin{array}{c}\text { TIPO DE } \\
\text { CONTEÚDO }\end{array}$} & \multicolumn{2}{|c|}{$\begin{array}{l}\text { GESTOS TÉCNICOS } \\
\text { Collet et al. (2007); Collet, Donegá e Nascimento (2009); Silva e Greco (2009); Ford, Yates e } \\
\text { Williams (2010); Lima, Martins-Costa e Greco (2011); Moreira, Matias e Greco (2013). }\end{array}$} \\
\hline & \multicolumn{2}{|c|}{$\begin{array}{l}\text { CONDUTAS TÁTICAS } \\
\text { Morales e Greco (2007); Morales, Greco e Andrade (2009); Collet, Donegá e Nascimento (2009); } \\
\text { Lima, Matias e Greco (2012); Moreira, Matias e Greco (2013); Pérez, Nivela e Expósito (2014). }\end{array}$} \\
\hline & \multicolumn{2}{|c|}{$\begin{array}{c}\text { FASE DE ATAQUE } \\
\text { Cañadas et al. (2009); Leite et al. (2011). }\end{array}$} \\
\hline \multirow[t]{2}{*}{ FASE DE JOGO } & \multicolumn{2}{|c|}{ 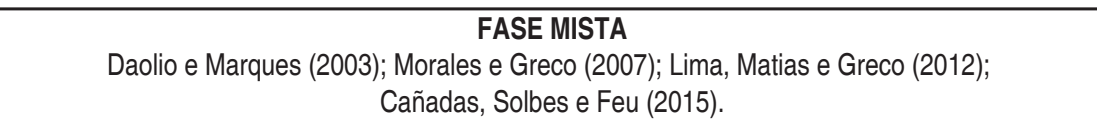 } \\
\hline & \multicolumn{2}{|c|}{$\begin{array}{c}\text { IGUALDADE NUMÉRICA } \\
\text { Daolio e Marques (2003); Morales e Greco (2007); Silva e Greco (2009); Lima, Martins-Costa e } \\
\text { Greco (2011); Leite et al. (2011); Cañadas et al. (2013); Moreira, Matias e Greco (2013); } \\
\text { Pérez, Nivela e Expósito (2014); Cañadas, Solbes e Feu (2015). }\end{array}$} \\
\hline $\begin{array}{l}\text { SITUAÇÕES } \\
\text { DE JOGO }\end{array}$ & $\begin{array}{l}\text { SUPERIORIDADE NUMÉRICA } \\
\text { Morales e Greco (2007); Cañadas et al. (2009); Collet, Donegá } \\
\text { e Nascimento (2009); Lima, Martins-Costa e Greco (2011); } \\
\text { Moreira, Matias e Greco (2013); Pérez, Nivela e Expósito (2014). }\end{array}$ & $\begin{array}{l}\text { INFERIORIDADE NUMÉRICA } \\
\quad \text { Morales e Greco (2007); } \\
\text { Pérez, Nivela e Expósito (2014). }\end{array}$ \\
\hline
\end{tabular}

Fonte: Elaborado pelos autores.

Quanto ao tipo de conteúdo, percebeu-se que os treinadores procuram trabalhar tanto os gestos técnicos quanto as condutas táticas, assim como privilegiar a fase de jogo mista (ataque e defesa simultaneamente) e a fase de ataque. Por fim, os treinadores têm procurado proporcionar tarefas de situações de jogo com desafios de igualdade numérica, seguidas por superioridade e inferioridade numérica.

Na Figura 3 podem ser observados os resultados relativos à variável organizativa, sendo que a participação consecutiva foi mais frequente do que a participação simultânea nas tarefas de treino.

Figura 3 - Resultados em termos de variáveis organizativas.

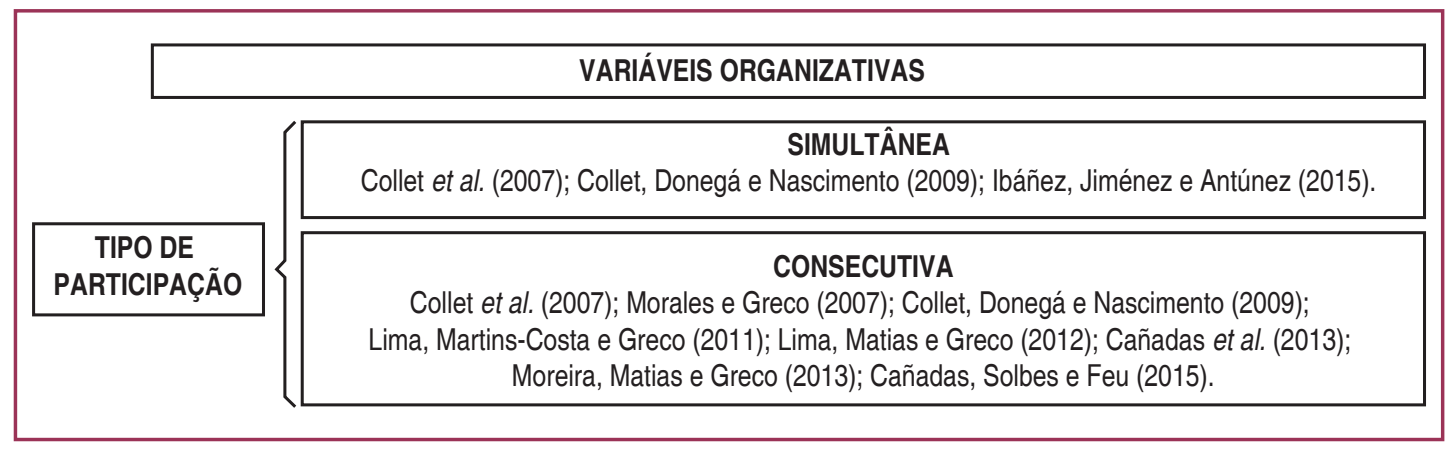

Fonte: Elaborado pelos autores.

\section{DISCUSSÃO}

As informações obtidas no mapeamento dos artigos empíricos, que analisaram a estrutura das tarefas de treino em categorias de formação de modalidades esportivas coletivas, revelaram 
que essa temática, ao mesmo tempo em que se apresenta como foco recente da pesquisa científica na área da Pedagogia do Esporte, também se destaca por seu crescimento nos cenários brasileiro e espanhol. Além de despertarem 0 aperfeiçoamento e 0 amadurecimento da análise do processo de treinamento técnico-tático (MACHADO; GALATTI; PAES, 2015; MENEZES; MARQUES; NUNOMURA, 2015), têm contribuído na estruturação das experiências motoras na preparação em longo prazo dos jogadores, procurando acompanhar modelos internacionalmente reconhecidos de formação esportiva (CÔTÉ; BAKER; ABERNETHY, 2003; CÔTÉ; FRASERTHOMAS, 2007; CÔTÉ; VIERIMAA, 2014; CÔTÉ; TURNNIDGE; VIERIMAA, 2016).

Neste contexto, reflete-se que a concentração de estudos que analisaram a estruturação das sessões de treinamento, no cenário científico brasileiro e espanhol, pode estar relacionada à presença da Pedagogia do Esporte nas linhas de pesquisa de grupos de estudos consolidados, com enfoque na investigação do processo de ensino-aprendizagemtreinamento de modalidades esportivas coletivas. Tal constatação leva à reflexão de que 0 estudo da estruturação do treinamento tem ainda baixa visibilidade e inserção em pesquisas no âmbito da Pedagogia do Esporte, área em consolidação nas Ciências do Esporte, em muitos países que se destacam no cenário esportivo internacional.

A concentração de estudos no Brasil e na Espanha, assim como nas modalidades esportivas foco das investigações encontradas, pode estar relacionada ainda à disseminação de instrumentos de coleta de dados validados para a investigação do tema, os quais foram difundidos nas pesquisas científicas no âmbitoda Pedagogia do Esporte, sobre a estrutura das sessões de treinamento, em ambos os países e que têm como foco a investigação das variáveis pedagógicas e organizativas de treino, em destaque nesta revisão sistemática. Dentre os instrumentos, destaca-se a Ficha de análise das sessões de treino apresentada por Stefanello (1999), a qual é utilizada na maioria das pesquisas sobre a temática na realidade brasileira, assim como o programa informático PyC Basket 2.0, referência na coleta de dados na realidade espanhola.

Um aspecto a ressaltar é que os principais estudos relacionados com a estruturação das tarefas retratam o cenário específico de algumas modalidades (basquete, vôlei, futsal e futebol), deixando de lado diversas práticas que fazem parte do âmbito esportivo mundial, como handebol, hóquei, rúgbi e futebol americano. Apesar de reconhecer que determinadas modalidades, por suas características e reconhecimento social, acabam gerando maior interesse investigativo, é evidente que o campo relacionado à análise das tarefas de treino pode e deve abranger outras modalidades menos difundidas em alguns países, como no caso brasileiro, proporcionando, consequentemente, uma melhor compreensão dos processos formativos que influenciam o desenvolvimento de jovens atletas em diferentes realidades $e$ distintos esportes, o que é fundamental tanto para a comunidade envolvida diretamente com esse fenômeno quanto para os próprios investigadores.

No que tange à concentração de estudos com equipes sub 12 e sub 13, considera-se que esta reflete o interesse dos pesquisadores pelas categorias iniciais de formação esportiva, especialmente pelo processo de treinamento oportunizado às crianças na transição entre os estágios de diversificação e especialização esportiva. Nesta etapa da formação esportiva ocorre uma maior preocupação com o desenvolvimento de habilidades esportivas específicas, maior intensidade das tarefas de treinamento, assim como maior comprometimento no envolvimento com o esporte por parte dos jovens atletas (CÔTÉ, 1999). 
Por outro lado, a predominância de investigações com atletas do sexo masculino reforça dados de revisão conduzida por Costello, Bieuzen e Bleakleyc (2014), os quais destacaram a disparidade de gênero na literatura esportiva, em que as mulheres estavam significativamente sub-representadas em todos os periódicos, quando observada a proporção de participantes, por sexo, em artigos publicados em periódicos da área da Medicina do Esporte. Os autores inferiram ainda que as mulheres geralmente respondem por um número inexpressivo do total de participantes de pesquisas originais e epidemiológicas. Além disso, evidenciaram que, historicamente, o esporte competitivo para as mulheres tem sido submetido a uma variedade de práticas discriminatórias.

A estruturação e a organização das tarefas de treinamento esportivo são fatores determinantes e que assumem um elevado grau de complexidade durante os treinos e devem assumir sua real importância durante todo o processo de treinamento técnico-tático (SAAD et al., 2015). Nesse cenário, as tendências atuais da Pedagogia do Esporte enfatizam que 0 processo de ensino não deve estar simplesmente centrado nas ações fechadas de repetição de habilidades motoras, mas proporcionar aos atletas um determinado grau de estímulo para que estes possam criar, diversificar e inovar durante o processo de treinamento (GALATTI et al., 2017).

As variáveis pedagógicas dentro do ambiente de treinamento exercem papel fundamental no processo de planejamento e execução das tarefas, pois são elas que determinam as características específicas do treino, como o tipo de conteúdo a ser trabalhado durante as atividades, se esta atividade será ofensiva ou defensiva, a relação que os atletas terão entre si, ou seja, esta variável explica como será o desenvolvimento do processo de estruturação das tarefas (IBÁÑEZ; FEU; CAÑADAS, 2016). Neste caso, a análise do tipo de conteúdo revelou que a estrutura das sessões de treino permanece sustentada em princípios analíticos (técnicos), apresentando assim divergência em relação às tendências mais atuais da Pedagogia do Esporte, pois, na maioria dos estudos investigados, os treinadores enfatizam tarefas voltadas para ações que priorizam os gestos técnicos. Sendo assim, evidencia-se a destinação de maior quantidade de tarefas pautadas na fragmentação das ações de jogo, proporcionando um limitado crescimento e amadurecimento dos atletas perante a real intenção dos esportes coletivos, que é a interação dos indivíduos com os outros e entre si (BAYER, 1994).

Os resultados encontrados nos artigos rastreados, no que tange à prioridade dada pelos treinadores às tarefas de treino sustentadas em princípios analíticos, revelam que, apesar dos avanços teóricos na área de Pedagogia do Esporte sobre a estruturação das sessões de treinamento, a prática profissional permanece alicerçada na reprodução de métodos tradicionais de ensino dos esportes. Essa sustentação da prática advém tanto do enfoque dado pelos treinadores à formação de seus atletas (metas formativas e competitivas traçadas para a equipe) quanto do fato de os princípios tradicionais de treino apresentarem determinada facilidade na elaboração e na organização das sessões de treinamento, bem como do fato de os treinadores estarem mais habituados e possuírem experiências mais consistentes com métodos mais analíticos. Além disso, evidenciam que ainda existe uma distância entre as abordagens teóricas propostas e a prática desenvolvida pelos treinadores, demonstrando que as investigações conduzidas não têm contribuído efetivamente para mudar a realidade dos treinamentos, para crianças e jovens, desenvolvidos em escolas e clubes de formação esportiva. 
Outro aspecto a ressaltar é que alguns treinadores também têm apresentado preocupação com a estruturação das tarefas de treino pautada nas condutas táticas, enfatizando-se um processo voltado para os componentes táticos, o qual visa desenvolver uma maior compreensão dos atletas em situações que se aproximam dos reais contextos que o esporte apresenta - situações-problemas e imprevisibilidade (MENEZES; MARQUES; NUNOMURA, 2014; MOREIRA; MATIAS; GRECO, 2013). Outro aspecto levantado entre os estudos que apresentam estes resultados é que os treinos, voltados para os princípios e aspectos táticos, fazem com que os jogadores aprimorem sua maneira de jogar, obtendo um elevado aumento de decisões mais coerentes durante os jogos (CAÑADAS; SOLBES; FEU, 2015; PÉREZ; NIVELA; ESPÓSITO, 2014). Nesta perspectiva, enfatiza-se a ideia de que 0 treinamento deve ser desenvolvido a partir dos componentes táticos, proporcionando para os atletas situações que estes poderão enfrentar na prática de uma partida real (MENEZES; MARQUES; NUNOMURA, 2015).

No que diz respeito às fases de jogo, percebeu-se que os treinadores têm enfatizado a fase mista e a fase de ataque, não se visualizando um foco único na fase de defesa. Neste contexto, uma característica que chama a atenção é que os treinadores têm a defesa como um fator secundário durante os treinos. Isso pode ser explicado pelo fato de que as ações ofensivas são mais motivadoras e estimulantes do que as ações defensivas (CAÑADAS et al., 2012), ou porque os treinadores podem supor que estão desenvolvendo os aspectos de defesa quando executam exercícios da fase de jogo mista, pois esta, de maneira intrínseca, pode vir a enfatizar este fator. Contudo, Ibáñez (2008) destaca que as ações de treino podem ser desenvolvidas por um processo ondulatório e contínuo, seguindo, assim, um desenvolvimento na distribuição dos conteúdos trabalhados, tendo como foco, em momentos diferentes, as fases de ataque, de defesa e mista.

$\mathrm{Na}$ análise das situações de jogo, observou-se que os treinadores enfatizam situações de igualdade ou superioridade numérica, buscando, assim, diversas situações-problemas e diferentes níveis de imprevisibilidade (CAÑADAS et al., 2013; MOREIRA; MATIAS; GRECO, 2013), revelando determinada proximidade às tendências da Pedagogia do Esporte que contemplam uma proposta compreensiva e tática das ações dos atletas (GALATTI et al., 2014). Deste modo, o oferecimento de situações de jogo diferenciadas compreende um fator preponderante na estruturação das sessões de treinamento, visando-se uma adequada progressão das tarefas a partir de variadas situações de jogo, as quais ocupam um papel fundamental no processo de facilitação da aprendizagem dos jogadores (CAÑADAS et al., 2013).

Para além das variáveis pedagógicas, os indicadores de organização das tarefas também fazem parte do amplo e complexo processo de treinamento esportivo, caracterizandose como ferramentas importantes para caracterizar o espaço a ser utilizado, como a tarefa será proposta, sua distribuição temporal, seus recursos e grupo de esportistas (IBÁÑEZ; FEU; CAÑADAS, 2016). No que tange ao tipo de participação, evidenciou-se nos estudos a participação massificada dos atletas em atividades de forma consecutiva ou alternada, com pouca participação de forma simultânea.

$\mathrm{Na}$ atualidade, o tipo de participação que o treinador planeja para os treinamentos é de suma importância para que os atletas vivenciem diferentes situações dentro do seu respectivo esporte. Cada participação tem o seu caráter distinto, sendo a simultânea o tipo 
que mais agrada aos jogadores, pois esta engloba todos os praticantes ao mesmo tempo em um exercício. Porém, treinos baseados em uma participação consecutiva podem fazer com que 0 atleta se concentre mais e diminua a quantidade de erros durante as ações. Uma forma de minimizar a ocorrência destes erros é proporcionar aos jogadores diferentes tipos de participações durante o treino (ALARCÓN; CÁRDENAS; UREÑA, 2008).

\section{CONSIDERAÇÕES FINAIS}

A presente revisão sistemática teve como objetivo mapear as investigações que analisaram a estrutura das tarefas de treino em equipes de categorias de formação de modalidades esportivas coletivas. A principal limitação foi a dificuldade de encontrar descritores coerentes com a temática foco da investigação e, consequentemente, os manuscritos nas bases de indexação selecionadas, cuja adversidade foi superada a partir da utilização dos procedimentos de busca secundária e terciária de informações.

Esta revisão revelou a atualidade da temática referente às tarefas de treino técnicotático no cenário das investigações científicas, o predomínio de estudos nas modalidades de basquetebol, voleibol, futsal e futebol, com atletas do sexo masculino e das categorias iniciais do processo de formação esportiva. Os estudos evidenciaram que as tarefas de treino, em termos de variáveis pedagógicas, têm sido focadas tanto no ensino dos gestos técnico-táticos quanto das condutas tático-técnicas (tipo de conteúdo), com predomínio de atividades voltadas para a fase mista (fases de jogo) e para as situações de igualdade numérica (situações de jogo). A análise da variável organizativa demonstrou a ênfase na participação consecutiva (tipo de participação) dos jogadores nas tarefas.

Apesar de revelarem avanços teóricos sobre a estruturação das sessões de treinamento, as evidências encontradas indicam que a prática profissional permanece ainda alicerçada na reprodução de métodos tradicionais de ensino dos esportes. Assim, investigações necessitam ser conduzidas para minimizar a distância entre as abordagens teóricas propostas e a prática desenvolvida pelos treinadores, contribuindo para mudar a realidade dos treinamentos de crianças e jovens.

0 mapeamento realizado das produções científicas relacionadas à estruturação das tarefas de treino aponta para a necessidade da continuidade das investigações sobre a implementação de modelos internacionalmente reconhecidos de formação esportiva em longo prazo, bem como recomendar a realização de investigações com atletas de categorias de formação mais próximas da categoria adulta e do sexo feminino. Além de priorizarem 0 conteúdo, a fase e as situações de jogo, os estudos necessitam favorecer uma melhor compreensão sobre o nível de oposição e os meios de treinamentos que caracterizam as variáveis pedagógicas e não identificadas nos artigos rastreados.

\section{REFERÊNCIAS}

ALARCÓN, Francisco; CÁRDENAS, David; UREÑA, Nuria. Influencia de los factores de organización de las tareas de aprendizaje sobre los tiempos de práctica del jugador de baloncesto. Apunts,

Educación Física y Deportes, v. 92, n. 1, p. 46-55, 2008. 
ATO, Manuel; LÓPEZ Juan J.; BENAVENTE, Ana. Un sistema de clasificación de los diseños de investigación en Psicología. Anales de Psicología, v. 29, n. 3, p. 1038-1059, 2013.

BAYER, Claude. 0 ensino dos desportos coletivos. Paris: Vigot, 1994.

BENJAMINSE, Anne et al. Motor learning strategies in basketball players and its implications for ACL injury prevention: a randomized controlled trial. Knee Surgery Sports Traumatology Arthroscopy, v. 25, n. 8, p. 2365-2376, 2017.

CAMPOS, Claudinei José Gomes. Método de análise do conteúdo: ferramenta para a análise de dados qualitativos no campo da saúde. Revista Brasileira de Enfermagem, v. 57, n. 5, p. 611-614, 2004.

CAÑADAS, Maria et al. Las situaciones de juego en el entrenamiento de baloncesto en categorías base. Revista Internacional de Medicina y Ciencias de la Actividad Física y el Deporte, v. 13, n. 45, p. 41-54, 2013.

CAÑADAS, Maria et al. Estudio de las fases de juego a través del análisis del entrenamiento deportivo en categoría minibasket. Cuadernos de Psicología del Deporte, v. 12, n. 2, p. 73-82, 2012.

CAÑADAS, Maria et al. Relationship between the pedagogical variables of coaching a mini-basketball team. Revista de Psicologia del Deporte, v. 18, suppl., p. 319-323, 2009.

CAÑADAS, Maria; SOLBES, Carlos; FEU, Sebastián. Analysis of training tasks regarding game stages and situations in U'10 and U'13 categories. Revista de Psicologia del Deporte, v. 24, n. 1, p. 13-15, 2015.

COLLET, Carine et al. Processo de ensino-aprendizagem-treinamento no voleibol infantil masculino em Santa Catarina. Revista da Educação Física, v. 18, n. 2, p. 147-159, 2007.

COLLET, Carine; DONEGÁ, André Luiz; NASCIMENTO, Juarez Vieira. A organização pedagógica do treino de voleibol: um estudo de casos em equipes mirins masculinas catarinenses. Motriz, v. 15, n. 2, p. 209-218, 2009.

COSTELLO, Joseph T.; BIEUZEN, Francois; BLEAKLEYC, Chris M. Where are all the female participants in Sports and Exercise Medicine research? European Journal of Sport Science, v. 14, n. 8, p. 847-851, 2014.

CÔTÉ, Jean. The influence of the family in the development of talent in sport. The Sport Psychologist, v. 13, p. 395-417, 1999.

CÔTÉ, Jean; BAKER, Joseph; ABERNETHY, Bruce. From play to practice: a developmental framework for the acquisition of expertise in team sport. In: STARKES, J. E.; ERICSSON, K. A. Expert performance in sports: advances in research on sport expertise. Champaign: Human Kinetics, 2003. p. $89-113$.

CÔTÉ, Jean; FRASER-THOMAS, Jessica. Youth involvement in sport. In: CROCKER, P. (Ed.). Sport Psychology: a Canadian Perspective. Toronto: Pearson, 2007. p. 270-298.

CÔTÉ, Jean; VIERIMAA, Matthew. The developmental model of sport participation: 15 years after its first conceptualization. Science \& Sports, v. 29, p. 63-69, 2014.

CÔTÉ, Jean; TURNNIDGE, Jennifer; VIERIMAA, Matthew. A personal assets approach to youth sport. In: GREEN, K.; SMITH, A. Routledge Handbook of Youth Sport. London and New York: Routledge, 2016. p. 243-255. 
DAOLIO, Jocimar; MARQUES, Renato Francisco Rodrigues. Relato de uma experiência com o ensino de futsal para crianças de 9 a 12 anos. Motriz, v. 9, n. 3, p. 169-174, 2003.

FICKLIN, Travis; DAPENA, Jesus; BRUNFELDT, Alexander. A comparasion of base running an sliding techniques in collegiate baseball with implications for sliding into first base. Journal of Sport and Health Science, v. 5, n. 3, p. 361-367, 2016.

FORD, Paul; YATES, lan; WILLIAMS, Mark. An analysis of practice activities and instructional behaviours used by youth soccer coaches during practice: Exploring the link between science and application. Journal of Sports Sciences, v. 28, n. 5, p. 483-495, 2010.

FORTES, Leonardo de Sousa et al. Efeito do treino mental no desempenho do arremesso de lance livre em jovens basquetebolistas. Motricidade, v. 13, n. 3, p. 4-12, 2017.

GALATTI, Larissa Rafaela et al. 0 ensino dos jogos esportivos coletivos: avanços metodológicos dos aspectos estratégico-tático-técnicos. Pensar a Prática, v. 20, n. 3, p. 639-654, 2017.

GALATTI, Larissa Rafaela et al. Pedagogia do esporte: contextos, evolução e perspectivas para 0 esporte paralímpico na formação de jovens. Corpoconsciência, v. 19, n. 3, p. 38-44, 2015.

GALATTI, Larissa Rafaela et al. Pedagogia do esporte: tensão na ciência e o ensino dos jogos esportivos coletivos. Revista da Educação Física, v. 25, n. 1, p. 153-162, 2014.

GUIZZO, Bianca Salazar; KRZIMINSKI, Clarissa Oliveira; OLIVEIRA, Dora Lúcia Leidens Correa. O Software QSR NVIVO 2.0 na análise qualitativa de dados: ferramenta para a pesquisa em ciências humanas e da saúde. Revista Gaúcha de Enfermagem, v. 24, n. 1, p. 53-60, 2003.

IBÁÑNEZ, Sérgio José; FEU, Sebastián; CAÑADAS, Maria. Sistema integral para el análisis de las tareas de entrenamiento, siate, en deportes de invasión. Revista de Ciencias del Deporte, v. 12, n. 1, p. 3-30, 2016.

IBÁÑEZ, Sérgio José. La planificación y el control del entrenamiento técnico-táctico en baloncesto. In: GONZÁLES, Julio Calleja; CEPEDA, Nicolás Terradas. Fisiología, Entrenamiento y Medicina del Baloncesto. Badalona: Paidotribo, 2008. p. 299-313.

IBÁÑEZ, Sérgio José; JIMÉNEZ, Adrian; ANTÚNEZ, Antonio. Differences in basketball training loads between comprehensive and technical models of teaching/training. Revista de Psicologia del Deporte, v. 24, suppl. 1, p. 47-50, 2015.

KUNRATH, Caito André et al. Avaliação da intensidade do treinamento técnico-tático e da fadiga causada em jogadores de futebol da categoria sub-20. Revista Brasileira de Educação Física e Esporte, v. 30, n. 2, p. 217-225, 2016.

LEITE, Nuno et al. Los contenidos de entrenamiento en baloncesto en función de las etapas de preparación deportiva a largo plazo. Revista de Psicología del Deporte, v. 20, n. 2, p. 287-303, 2011.

LIMA, Cláudio Olívio Vilela; MARTINS-COSTA, Hugo Cezar; GRECO, Pablo Juan. Relação entre o processo de ensino-aprendizagem-treinamento e o desenvolvimento do conhecimento tático no voleibol. Revista Brasileira de Educação Física e Esporte, v. 25, n. 2, p. 251-261, 2011.

LIMA, Cláudio Olívio Vilela; MATIAS, Cristiano Julio Alves da Silva; GRECO, Pablo Juan. O conhecimento tático produto de métodos de ensino combinados e aplicados em sequências inversas no voleibol. Revista Brasileira de Educação Física e Esporte, v. 26, n. 1, p. 129-147, 2012. 
MACHADO, Thais do Amaral et al. Ansiedade estado pré-competitivo em atletas de voleibol infantojuvenis. Revista Brasileira de Educação Física e Esporte, v. 30, n. 4, p. 1061-1067, 2016.

MACHADO, Gisele Viola; GALATTI, Larissa Ragaela; PAES, Roberto Rodrigues. Pedagogia do esporte e o referencial histórico-cultural: interlocução entre teoria e prática. Pensar a Prática, v. 17, n. 2, p. 414-430, 2014.

MACHADO, Gisele Viola; GALATTI, Larissa Ragaela; PAES, Roberto Rodrigues. Pedagogia do esporte e projetos sociais: interlocuções sobre a prática pedagógica. Movimento, v. 21, n. 2. p. 405418, 2015.

MENEZES, Rafael Pombo; MARQUES, Renato Francisco Rodrigues; NUNOMURA, Myrian. Especialização esportiva precoce e o ensino dos jogos coletivos de invasão. Movimento, v. 20, n. 1, p. 351-373, 2014.

MENEZES, Rafael Pombo; MARQUES, Renato Francisco Rodrigues; NUNOMURA, Myrian. 0 ensino do handebol na categoria infantil a partir dos discursos de treinadores experientes. Movimento, v. 21, n. 2, p. 463-477, 2015.

MONTERO, Ignacio; LEÓN, Orfélio Garcia. A guide for naming research studies in Psychology. International Journal of Clinical and Health Psychology, v. 7, n 3, p. 847-862, 2007.

MORALES, Juan Carlos Pérez; GRECO, Pablo Juan. A influência de diferentes metodologias de ensino-aprendizagem-treinamento no basquetebol sobre o nível de conhecimento tático processual.

Revista Brasileira Educação Física e Esporte, v. 21, n. 4, p. 291-299, 2007.

MORALES, Juan Carlos Pérez; GRECO, Pablo Juan; ANDRADE, Ricardo Leão. A description of the teaching-learning processes in basketball and their effects on procedural tactical knowledge. Revista de Psicologia del Deporte, v. 8, suppl., p. 469-473, 2009.

MOREIRA, Valmo José Penna; MATIAS, Cristiano Julio Alves da Silva; GRECO, Pablo Juan. A influência dos métodos de ensino-aprendizagem-treinamento no conhecimento tático processual no futsal. Motriz, v. 19, n. 1, p. 84-98, 2013.

PEIXOTO, Giuliano Flint et al. Correlação entre composição corporal, potência e agilidade das jogadoras de handebol da cidade Americana-SP. Revista Brasileira de Prescrição e Fisiologia do Exercício, v. 10, n. 61, p. 679-683, 2016.

PÉREZ, Elena Escolano; NIVELA, Maria Luiza Herrero; EXPÓSITO, Rocío Echeverría. La resolución de problemas como estrategia de enseñanza para el aprendizaje de la táctica ofensiva en la categoría pre-benjamín de fútbol 8. Revista de Psicología del Deporte, v. 23, n. 1, p. 2092017, 2014.

SAAD, Michel Angillo et al. Estrutura das sessões de treinamento técnico-tático de esquipes de futsal sub-13 e sub-15 ao longo da temporada esportiva. Revista Brasileira de Futsal e Futebol, v. 7, n. 25, p. 360-365, 2015.

SAUR-AMARAL, Irina. Revisão sistemática da literatura com apoio de EndNote e NVivo. Aveiro: Bubok, 2012.

SILVA, Marcelo Vilhena; GRECO, Pablo Juan. A influência dos métodos de ensino-aprendizagemtreinamento no desenvolvimento da inteligência e criatividade tática em atletas de futsal. Revista Brasileira Educcação Física e Esporte, v. 23, n. 3, p. 297-307, 2009. 
STEFANELLO, Joice Mara Facco. A participação da criança no desporto competitivo: uma operacionalização e verificação empírica da proposta teórica de Urie Bronfenbrenner. 1999. 396 f.

Tese (Doutorado) - Faculdade de Ciências do Desporto e Educação Física, UC, Coimbra, 1999. 